\title{
INTRODUCTION TO THE THEORETICAL ANALYSIS OF SOCIAL EXCLUSION OF PUBLIC TRANSPORT IN RURAL AREAS
}

\author{
József Pál LIESZKOVSZKY
}

\begin{abstract}
${ }^{a}$ Széchenyi István University, Győr, Doctoral School of Regional and Economic Sciences, Corvinus University of Budapest, Institute of Geography Geoeconomy and Sustainable Development, e-mail: jozsefpal.lieszkovszky@uni-corvinus.hu
\end{abstract}

Cite this article: Lieszkovszky, J. P. (2018). Introduction to the theoretical analysis of social exclusion of public transport in rural areas. Deturope, 10(3), 214-227.

\begin{abstract}
Western societies are facing the same problems worldwide regarding the provision of public transport services in rural, sparsely populated and peripheral areas. One of the main reasons is that due to the increasing number of cars (which can satisfy the mobility needs much better), the number of passengers of public transport services are steadily decreasing (ITF, 2015). However, we do not forget that supplying these areas with public transportation have in fact always been problematic: the dispersed settlement network is a given fact as well as the low population density that never generated high demand (Ambrosino, Nelson \& Romanazzo, 2003).

Passengers of public transport in rural areas are not classified by the majority of international literature as voluntary travellers on public transport vehicles, but who belong to those groups which stand in need of travelling by them. Regarding this issue, the major starting-point is the ability to have access to car which can be modified by other factors (financial situation, sex, age, physical condition, type of household, foreign language skills etc.). Those people who have limited or no access to car are thus constrained by the schedule of public transport vehicles and depend on its reliability or even no access to any transport mode belongs to the group of transport deprived.

The purpose of this article is twofold: to introduce those groups who are suffering from the decline of public transport in rural areas and to highlight the necessity of these researches in Central and Eastern Europe.
\end{abstract}

Keywords: Public transport, Rural areas, Transport related social exclusion, Transport poverty

\section{INTRODUCTION}

Transport accessibility is one of the most important issues for the people living in rural areas, since they need to use some means of transport (individual or public) to reach almost all existing activities, which is a cardinal issue, especially in those areas where quality education or health service networks do not exist at all and the number of local jobs are relatively constrained (SEU, 2003).

Passengers of public transport in rural areas are not classified by the majority of international literature as voluntary travellers on public transport vehicles, but who belong to those groups which stand in need of travelling by them. Regarding this issue, the major 
starting-point is the ability to access to car which can be modified by other factors (financial situation, sex, age, physical condition, type of household, foreign language skills etc.) (Gašparović, 2016; Stanley \& Stanley, 2004; Chapman \& Doug 2008; Ferreira, Charles \& Tether, 2007). In addition, the factors are overlapping each other. Moreover, the demand side in rural areas is characterized by strong fragmentation, since the main social groups of users (young people, the elderly, the disabled, etc.) have different needs in terms of both time (morning peak, daytime, afternoon) and their purposes (employment, education, shopping, healthcare, etc.). Again, the number of passengers on public transport is steadily declining, which is a problem not only in Central and Eastern Europe, but also in the developed Western European countries, where it was an existing phenomenon in the 70s and 80s (Erdösi, 2000). This decline is caused not only by the growing number of cars but the rural depopulation and the decrease of natural growth, as well (Ambrosino, Nelson \& Romanazzo, 2003).

Those social groups which are the most affected by the decline of public transport have been forced into a kind of exclusion status. This form of social exclusion is called transport poverty or transport related social exclusion (e.g. Preston \& Rajé, 2007; Stanley \& Lucas, 2008; Rankovic Plazinic \& Jovic, 2014; Pyrialakou, Gkritza, \& Fricker, 2016).

During the compilation of this thesis, I leaned mainly on Western European literatures because there are very few relevant literatures published by Eastern and Central European authors. This shortage was a particularly inhibitive factor for me.

In line with the foregoing, the aim of the article is twofold: on the one hand, to show those groups who are suffering from the decline of public transport in rural areas. And, on the other hand, to highlight the lack of researches on the social aspect of public transport from Central and Eastern Europe.

\section{LITERATURE REVIEW}

\section{Definition of social exclusion}

The definition of social exclusion has abundant literature (Kenyon et al., 2002; Preston \& Rajé, 2007; Stanley \& Lucas; 2008; Cass, Shove \& Urry, 2003). The most accurate definition is given by the researchers from the LSE (London School of Economics): an individual is considered to be socially excluded if (s)he does not participate in social activities from time to time but at the same time (s)he wants to join them, however something prevents her/him from participating in them (Stanley \& Vella-Broderick, 2009; Shergold \& Parkhurst, 2012).

Social exclusion can be measured in five different dimensions (Currie \& Delabosc, 2010):

1. income of the individual / household 
2. exclusion of the individual from the labor market (job seeker or diseases of the unemployed)

3. lack of access to basic services (e.g. electricity, transport, water, gas)

4. lack of social activities, social isolation, willingness to social support, lack of involvement in the civil sector etc.

5. physical inability to leave the apartment

It can be seen that the lack of access to transport (as a basic service) is also mentioned as a major dimension of social exclusion, but its impact is much greater because it has an important role in other dimensions, as well (Kenyon et al., 2002). The lower the status of the individual is, the more dimensions (s)he is involved in, and it is more likely that the access to any basic activities can be delivered not by car but by public transport. In addition, the poor transport supply itself can also create a social-excluded situation, which hits those social groups in an unfortunate way who are affected by more dimensions of social exclusion (CTA, 2003). Hereinafter, social exclusion is presented from the point of view of transport.

\section{Definition and appearance of transport exclusion}

The transport-related researches - carried out mainly by engineers and transport economists - neglected the social aspect until the beginning of 2010. At the same time - as part of social exclusion - traffic-based exclusion at the public policy level has been dealt with since the late 1990s (first in the United Kingdom to government order) (Fransen et al., 2015).

Since then most of the researches in this issue are listed by scientists of the UK but it is also significant in Australia and in the Scandinavian countries, however, it has not yet been in the focus of research in the US (Jeekel, 2014). Unfortunately, in Central and Eastern Europe, apart from a few exceptions, a relevant literature is not available (as mentioned before).

Transport related exclusion can be briefly identified by positing that the person does not have the suitable access to any means of transport to reach the place where important social activities are taking place in which (s)he would participate in (Meert, 2003). In other words, the person is unable to travel wherever and whenever others can get through without difficulty (Pyrialakou et al., 2016).

There are six categories of exclusion connected to transport by Church, Frost, and Sullivan (2000)

1. physical exclusion (where physical barriers inhibit the accessibility of services which could be experienced by mothers with children, elderly or frail etc.) 
2. geographical exclusion (where poor transport provision and resulting inaccessibility can create exclusion)

3. exclusion from facilities (the distance of facilities - e.g. shopping, health, leisure, education - from people's homes, especially from those with no car, make access difficult)

4. economic exclusion (the high costs of travel can prevent or limit access to facilities or jobs and thus income)

5. time-based exclusion (where other demands on time such as caring restrict the time available for travel)

6. fear-based exclusion (where worry, fear and even terror influence how public spaces and public transport are used, particularly by women, children and the elderly)

However, it is not easy to define and quantify who is suffering from transport exclusion, as relevant data can only be reached for area units, although this phenomenon can be found at individual and household levels, as well. Moreover, what "good access" means is not easy to determine, because it can have a different meaning in each social group as well as by individuals: reaching the educational sites is more important for students than older people; in contrary, the access to care institutions is much more important for the older generations (Fransen et al., 2015).

\section{The factors of potential access to car}

One of the crucial bases of transport exclusion is the possibility of access to car concerning the individual. There are two theoretical forms of car dependency (structural and comfort) which are closely related to the local level of public transport:

- Comfort addicts are those individuals who have other accesses but for some reasons (e.g. comfort or freedom) they prefer to choose car.

- Structurally dependent individuals use their own cars because there is no other means of transport (e.g. bus or train) to reach their destinations; or if it does exist, does not provide a realistic alternative to car.

A specific group of structurally dependent individuals is the "constraint car owners", who are mainly the residents of low-status households in rural areas with no adequate public transport. These households would not otherwise maintain a car but they have to - due to 
public transport being unusable - and this is a tremendous financial burden for them (Pyrialakou et al., 2016).

In rural areas, it is even more important to maintain an own car (or access to it), because without a car it is difficult or impossible to reach (Gašparović, 2016; Kenyon et al., 2002)

- shopping centres in the suburban areas of cities without bus connections or if it exists, the connection is between the shopping centre and the city centre only.

- the non-priority healthcare centers or workplaces located not on the main public transport routes;

- workplaces where working time is not between 8 to 18 , but starts or ends much earlier or later (e.g. workplaces with two or three-shift schedules), therefore, the employees (inward/outward or both cases) are not sure to use public transport vehicles, and privately organized bus services (running at the end and start of the shifts) do not operate either;

- workplaces where weekend work is also taking place; and whose locations are also far from the major public transport routes;

- each such service which ends after 8-10 pm. in the city or is performed in the weekends (in which cases the inward route can also be problematic).

Based on the above, it can be concluded that the absence of access to car causes both spatial and time (dimensional) barriers for the individual to achieve the desired activities. Moreover, in many cases, it is realized only in one direction (inward or outward) making it even more difficult to organize the journey. So, the availability (as well as directions and frequencies) of public transport vehicles are cardinal (out of necessity) in the everyday life of those people who suffer from the lack of access to car. Thus, these people must adapt their lives almost completely to the schedule of public transport services which is a crucial cornerstone for them, so it can be declared that their free movements are limited and impaired in a sense. Undoubtedly, residents of those settlements are in the most disadvantaged situation where no public transport services are available at all.

It is important to note that as long as jobs and educational institutions are visited regularly (daily or at least five times a week on business days / school days); the demand for access to other services is required much less and rather irregularly. There are, of course, several exceptions regarding the mode of the required services which can be forced (e.g. someone must visit the hospital for treatment on a given day, every week) or optional (e.g. shopping or visiting friends one week on Tuesdays or another week on Thursdays, too). In the latter case, 
it should be taken into account that the realization of optional activities is determined by the timetables of public transport services, so from one aspect, they are actually "forced" to happen (e.g. there are buses only on Tuesdays or suitable possibilities of further connections with which the relatives can be visited and the outward route back to home is possible, as well).

\section{Relativity of public transport demand}

The public transport demand itself is quite relative as it depends on the accessibility of the given settlement and its social structure. In those settlements which can be easily reached by any kind of public transport modes, life can be relatively convenient without having a car. However, the residents of settlements supplied with less public transport ("less public transport equipped" settlements) are heavily reliant on the use of cars, which may be due to the fact that the needed services are not located in one central settlement but can be found scattered in the surrounding areas (in the surrounding bigger settlements/cities) and the accessibility of those cities is not always managed equally by public transport services (Litman, 2003). In these communities, people without cars are more vulnerable to the possibility of transport exclusion and therefore to a wider exclusion, too. It is also worth mentioning that the phenomenon of transport exclusion cannot be necessarily perceived in settlements having a good level of services but having insufficient public transport possibilities (Pyrialakou et al., 2016).

It is not easy to determine who are considered as disadvantaged in a settlement, since the transport needs of different social groups differ regarding space and time.

As an example, it is possible that public transport services give appropriate access for pupils to reach school regarding both time (morning and after school-time) and space (inward to school and outward to home), and, at the same time, it is also convenient for the elderly regarding space, but not necessarily in time. Thus, those elderly people who want to get to a settlement which provides social and health care (e.g. outpatient clinic) for them are supplied with typically mid-day inward and mid-afternoon outward journeys. If there is no suitable means of public transport access for the elderly regarding both time and space - e.g. to the outpatient clinic located in the city - the elderly residents of the given settlement will be affected by transport exclusion regardless of the situation of the given settlement in the public transport network. This is the case since an important service for their livelihoods can only be taken with more financial expenditure (e.g. they have to use a taxi) and much longer time to get there (e.g. they have to change between the transport services even several times). Thus, 
transport exclusion can also be applied to people or groups who are unable or do not want to access public transport services because they run to inappropriate destinations and/or at not suitable times (Gašparović, 2016).

Based on the above, it can be detected that different groups of society are affected by the risk of transport exclusion to different extents depending on the public transport location of the given settlement and the possible access to the surrounding major centers (Kenyon et al., 2002).

\section{CLASSIFICATION OF SOCIAL GROUPS AFFECTED BY SOCIAL EXCLUSION IN PUBLIC TRANSPORT}

It is essential to present the social groups in detail who are concerned in transport exclusion. These groups can be classified in lots of ways, I will use three such classifications: A) age, B) sex, C) income status. ${ }^{43}$

A) age

\section{$\underline{1 .}$ Small children (0-4) and their guardians}

The kindergarten and child care facilities are the most important among their destinations, and obviously, small children are always travelling with adult supervision. It is a problem especially for the adults - to take their carriages onto the bus/train so they are - besides the people living with disabilities - the ones who particularly urge that low-floor buses should be introduced (Stanley \& Stanley, 2004).

\section{Youths between 5 and 16 years of age}

Their destinations include school and post-school activities (e.g. sports clubs, swimming pools, etc.). Most of the public transport services are made up for them and not just during the school term, but school holidays, as well, especially during daytime periods. It is a problem for them that there are no public transport services (which are suitable for them regarding time and space) to the location of post-school activities. In addition, they expect the last buses to depart later from the cities and would like more dense public transport provision on Saturdays (Stanley \& Stanley, 2004).

\footnotetext{
${ }^{43}$ The public transport demands of people with disabilities are not discussed in this paper as their cases are quite specific and complex.
} 
When the parents choose an appropriate high school for their children, it is also necessary to consider how the children get there if the household does not have such a car which they can regularly be carried with. The farther the young person lives from the school, the longer (s)he needs to spend on public transport vehicles, so learning and refreshing themselves (regeneration) takes less time. Youths between 14 and 16 are more likely to use the public transport services from constraint, because they do not yet have the driving license and they have no earnings either. Furthermore, it is important to mention that households (with young people and) with cars can travel anywhere on weekends but for households without a car this is less possible due to the deficient public transport provision on weekends (Gašparović, 2016).

\section{Young adults (up 16 years of age)}

Older teenagers and young, already working adults belong to this sub-group. They might have a driving license considering their age, but they do not have their own cars for financial reasons, or if the household even has one, it is used by the head of family for daily commuting. Their destinations can be either secondary and higher education institutions, unemployment centers or low-paid workplaces. The recreational trips among them are just as important as for the elderlies. If they can no longer benefit from travel allowances (because of their age), they will have to pay much more money for the travel (Cartmel \& Furlong, 2000).

\section{$\underline{4 . \text { Elderlies }}$}

The proportion of elderlies in our society is steadily increasing worldwide, so their expectations are more and more important regarding public transport. Their mobility needs to differ from those of the groups discussed above in many segments (e.g. they specifically require non-conventional public transport provision, the long walking to the bus station is uncomfortable for them etc.). Their relationship to cars changes by continents. Among other things, this means that older people in the heavily vehicularized cultures (USA, AUS) use their cars until their health permits (Nutley, 1996; 2003).

For the elderlies, access to shopping, social-health and recreational facilities is primary, so the proportion of early morning / late-night and weekend trips (except for Sunday family visits and religious trips) is low among them, therefore the existence of these accesses are not as important as for the youth. What can pose problems to them in particular include the low proportion of low-floor buses, the long waiting time for buses in uncovered stops, the absence 
of a direct public transport provision to local hospital, clinic, bigger pharmacy, post office, doctor (Stanley \& Stanley, 2004).

There is a special group of wealthy elderly people with cars who moved to rural areas for their retired years. But due to illness, invalidism or death of the partner with driving license they are no longer able to use up the benefit of the car, thus, they increase the number of people living in transport exclusion. According to Tolley \& Tourton (1995), their numbers are not negligible, in the UK it is $1 / 3$ of the rural population.

\section{B) Sex}

\section{$\underline{\text { Women }}$}

Women's travel needs are much more complex compared to men's, as their activities related to household and child care induce far more travel (Noack, 2011), however, these travels are much shorter than the commuting journey to work of the family head (SEU, 2003). In the case of the women, the most important aspect is the number of cars in the household: if there are two, then they are in a more advantageous position because they can use the car without problems; but if the family has only one, then it is most likely to be used by the family head for daily commuting purpose. Thus, regarding transportation, the situation of women in onecar families are not far better (than where is no car at all) so they might be affected by transport exclusion, too (Rankovic Plazinic \& Jovic, 2014).

Housewives using public transport services have to face further problems: most of the activities (e.g. shopping etc.) take place in peak hours when the public transport provision is infrequent (those women taking care of elderlies or cleaning up in daytime or in late evenings / early mornings face similar problems).

Researches have shown that in many Western European countries (e.g. in the UK) it is essential for women to have their own cars and with them they are able to carry out their tasks regarding work, household activities, child care in the same time etc. In addition, women have a lower share of owning a driving license than men (this gap is being decreased towards the developed countries), but women are more likely to be public transport oriented. For this reason, women in rural areas have lower chances to find well-paid jobs (Gašparović, 2016). One of the solutions to these problems can be the implementation of their tasks in a flexible way. It means the support of part-time work from the employers and demand responsive 
transport provision from the side of public transport service providers (Granson, 2011; Siren, 2006).

A special group is formed by immigrant women who have relatively little information on their problems and even less scientific researches. For cultural reasons or because of the fear of all kinds of oral or physical atrocity, they already use the public transport services only in the most necessary cases. Moreover, it can be difficult to be understood (e.g. by the bus driver) because of the lack (or low knowledge) of local language (Social exclusion and the provision of public transport - Main report).

\section{C) Financial situation}

\section{$\underline{1 . \text { Unemployed and jobseekers without a car }}$}

One of the most heterogeneous groups, their situation resembles the status of young adult jobseekers in many cases, however, these people - because of their age - are less able to seek help from their parents. The hardest problem for them is the failure to reach the potential workplaces with public transport services, and this negative effect can be further increased by the tight schedule supply and its relatively high cost. Again, the lack of early morning and late evening buses, as these people (due to their low level of qualifications) mainly apply for 2 or 3 shift jobs. In traditional industrial areas this problem is even more complicated: these cities used to offer plenty of workplaces to the residents, there were traditions of local employment, but they no longer provide job opportunities as a result of the economic collapse of these areas (both in Western and Eastern Europe) (Cartmel \& Furlong, 2000).

According to a survey from 1999, the job seekers in the UK did not get the job because $52 \%$ of them could not get to work individually and $23 \%$ of them had no public transport provision to their future workplaces (Social exclusion and the provision of public transport Main report).

In most cases there are no public transport provision on weekends - especially on Sundays - and generally for shifts starting early morning, so these young people involved have to solve this problem (e.g. call a taxi etc.) which is not economically viable in the long term. For this reason, many employers prefer candidates who are able to solve to reach the workplace individually - this is also a rather tangible example of transport exclusion (Cartmel \& Furlong, 2000). 
Overall, it can be concluded that ensuring adequate public transport in time and space provides completely new opportunities for job seekers, which is a very important aspect in areas where the unemployment rate is high.

\section{Low-status families without a car}

Similarly, it is a problem for them to get to the workplace in time, but in their case, it is not just theory, but have to be done in practice. And in these cases, the public transport vehicles have to be on time and exist in early mornings and late evenings, as well. Furthermore, the recreational programs can only be reached by public transport vehicles, which, in many cases, can be very exhausting and circuitous on weekends. Inauguration of demand responsive transport systems can fix this problem.

However, a struggling situation can occur not only on weekends and daytime, but if the employee travels by such a bus - even in one direction - which runs only in school-time, (s)he has to find another solution to reach his/her workplace in school vacation. As a result, in most cases, the employees with mobility difficulties have to ask e.g. one of their family members or friends to drive them to work or ask anybody to lend them a car. In addition, in rural areas not only the employment, but other training opportunities are constrained for the residents if there is no public transport provision to the location of the training (Social exclusion and the provision of public transport - Main report).

Both above-mentioned groups may ask a lift from anyone (e.g. friends) who has a car, but this may lead to dependence on others, which is more of an inconvenience for many than an advantage, so if it is possible, this form of transport will be ignored (Gašparović, 2016).

\section{Transport exclusion in a wider context}

Rankovic Plazinic and Jovic (2014) examines the exclusion from a wider context (from economic, socio-cultural and transportation aspects) in rural areas, and find as a result of their research that there is a vicious circle among the transport, economic and socio-cultural exclusions whose basis is the lack of a car. This situation results in an immediate transport exclusion and due to it, it is much harder to find a (well-paid) job, because these workplaces are found mainly in larger settlements. If the application of a job-seeker for a well-paid job does not lead to results, $\mathrm{s}(\mathrm{he})$ will have to accept a less paid local job or in a worse scenario the unemployment benefit. Therefore, the economic position of an individual is getting worse and worse so s(he) becomes economically excluded, too (Rankovic Plazinic \& Jovic, 2014). The effect of different aspects on each other is illustrated by the following table: 
Table 1 The impact of different aspects of social exclusion

\begin{tabular}{|l|l|l|}
\hline $\begin{array}{l}\text { The origin of } \\
\text { exclusion }\end{array}$ & $\begin{array}{l}\text { The effect of other } \\
\text { exclusion }\end{array}$ & The individual... \\
\hline Economic & to cultural & $\begin{array}{l}\text { has low salary, so (s)he does not allow to } \\
\text { participate in social and cultural activities }\end{array}$ \\
\hline Economic & to transportation & $\begin{array}{l}\text { has no money to buy and maintain a car, so (s)he } \\
\text { depends on the public transport provision }\end{array}$ \\
\hline Transportation & to economic & $\begin{array}{l}\text { has no car (and there is no appropriate public } \\
\text { transport provision for him/her), so (s)he has got } \\
\text { less chance to find a (well-paid) job }\end{array}$ \\
\hline Cultural & to cultural & $\begin{array}{l}\text { has no car (and there is no appropriate public } \\
\text { transport provision for him/her), so (s)he cannot } \\
\text { maintain his/her cultural life (e.g. going to } \\
\text { cinema) and social relations located in further } \\
\text { cities }\end{array}$ \\
\hline Cultural & to economic & $\begin{array}{l}\text { visits no more social events, so his/her } \\
\text { relationships with distant acquaintances are } \\
\text { getting lost, and even some of his/her abilities } \\
\text { are also forgotten, so (s)he has even less chance } \\
\text { to find a (well-paid) job. }\end{array}$ \\
\hline to transportation & $\begin{array}{l}\text { lost touch with some of his/her relations, distant } \\
\text { acquaintances and friends, which has an impact } \\
\text { on his/her local social connections, so reluctantly } \\
\text { asks for any help (e.g. a lift) to get anywhere. }\end{array}$ \\
\hline
\end{tabular}

Source: Author's elaboration based on Rankovic Plazinic \& Jovic (2014)

\section{CONCLUSION}

Transport related exclusion can be briefly identified by positing that the person does not have the suitable access to any means of transport to reach the place where important social activities are taking place in which (s)he would participate in. One of the crucial bases of transport exclusion is the possibility of access to car concerning the individual, which can be structural or comfort. A specific group of structurally dependent individuals is the "constraint car owners", who are mainly the residents of low-status households in rural areas with no adequate public transport. These households would not otherwise maintain a car, but they have to - due to public transport being unusable - and this is a tremendous financial burden for them. Those social groups are concerned in transport exclusion who have reduced mobilities because of various reasons. These groups can be classified in lots of ways (e.g. age, sex, income status).

For the elderlies, access to shopping, social-health and recreational facilities is of primary relevance, so the proportion of early morning / late-night and weekend trips (except for 
Sunday family visits and religious trips) is low among them, therefore, the existence of these accesses is not as important as for the youth.

Regarding the women, their travel needs are much more complex compared to men's, as their activities related to household and child care induce far more travel, however, these travels are much shorter than the commuting journey to work of the family head. In the case of the women, the most important aspect is the number of cars in the household: if there are two, then they are in a more advantageous position, because they can use the car without problems; but if the family has only one, then it is most likely to be used by the family head for daily commuting purpose. Thus, regarding transportation, the situation of women in onecar families are not far better (than where is no car at all), so they might be affected by transport exclusion, too.

\section{REFERENCES}

Ambrosino, G., Nelson, J. D., \& Romanazzo, M. (2003). Demand Responsive Transport Services: Towards the Flexible Mobility Agency. Italian National Agency for New Technologies, Energy and the Environment.

Cartmel, F., \& Furlong, A. (2000). Youth unemployment in rural areas. Joseph Rowntree Foundation.

Cass, N., Shove, E., \& Urry, J. (2003). Changing Infrastructures. Measuring Socio-Spatial Inclusion/Exclusion, report for DfT. Lancaster: Lancaster University, Department of Sociology.

Chapman, S., \& Doug W. (2008). Accessibility planning methods. NZ Transport Agency Research Report 363. Wellington: NZ Transport Agency.

Church, A., Frost, M., \& Sullivan, K. (2000). Transport and social exclusion in London. Transport Policy, 7(3), 195-205.

Community Transport Association (CTA) (2003). A guide to Demand Responsive Transport for rural Community Transport operators. The CTA Rural Good Practice Guide series, No 7. DRT.

Currie, G., \& Delabosc, A. (2010). Modelling the social and psychological impacts of transport disadvantage. Transportation, 37(6), 953-966.

Erdősi, F. (2000). A kommunikáció (közlekedés-távközlés) szerepe a terület- és településfejlödésben. Budapest: VÁTI Kht.

Farrington, J., Gray, D., Martin, S., \& Roberts, D. (1998). Car Dependence in rural Scotland: Challenges and Polices. Edinburgh: Central Research Unit HMSO, Scottish Office.

Ferreira, L., Charles, P., \& Tether, C. (2007). Evaluating Flexible Transport Solutions. Transportation Planning and Technology, 30 (2-3), 249-269.

Fransen, K., Neutens, T., Farber, S., De Maeyer, P., Deruyter, G., \& Witlox, F. (2015). Identifying public transport gaps using time-dependent accessibility levels. Journal of Transport Geography, 48, 176-187.

Gašparović, S. (2016). Theoretical Postulates of Transport Disadvantage. Hrvatski Geografski Glasnik, 78(1), 73-95.

International Transport Forum (2015). International Experiences on Public Transport Provision in Rural Areas [Pdf]. Retrieved from https://www.itfoecd.org/sites/default/files/docs/15cspa_ruralareas.pdf 
Jeekel, H. (2014). Social exclusion, vulnerable groups and driving forces: towards a social research based policy on car mobility. Soc. Exclusion Ctries. Adv. Transp. Syst., 2(2), 96-106.

Kenyon, K., Lyons, G., \& Rafferty, J. (2002). Transport and social exclusion: investigating the possibility of promoting social exclusion through virtual mobility. Journal of Transport Geography, 10, 207-219.

Meert, H., Bourgeois, M., Van Hoof, K., \& Asperges, T. (2003). Immobiel op het platteland. Omtrent rurale vervoersarmoede in Vlaanderen. Brussel: Koning Boudewijnstichting.

Noack, E. (2011). Are rural women mobility deprived? case study from Scotland. Sociologia Ruralis, 51(1), 79-97.

Nutley, S. D. (1996). Rural transport problems and non-car populations in the USA. Journal of Transport Geography, 4, 93-106.

Nutley, S. D. (2003). Indicators of transport and accessibility problems in rural Australia. Journal of Transport Geography, 11, 55-71.

Preston, J., \& Rajé, F. (2007). Accessibility, mobility and transport-related social exclusion. Journal of Transport Geography, 15, 151-160.

Pyrialakou, V. D., Gkritza, K., \& Fricker, J. D. (2016). Accessibility, mobility, and realized travel behavior: Assessing transport disadvantage from a policy perspective. Journal of Transport Geography, 51, 252-269.

Rankovic Plazinic, B., \& Jovic, J. (2014). Women and transportation demands in rural Serbia. Journal of Rural Studies, 36, 207-218.

Shergold, I., \& Parkhurst, G. (2012). Transport-related social exclusion amongst older people in rural Southwest England and Wales. Journal of Rural Studies, 28, 412-421.

Social exclusion and the provision of public transport - Main report. Department of Transport. University of North London [pdf]. Retrieved from http://test.ricerchetrasporti.it/wp-content/uploads/downloads/file_459.pdf.

Social Exclusion Unit (SEU) (2003). Making the Connections: Final Report on Transport and Social Exclusion. London: HMSO, Office of the Deputy Prime Minister.

Stanley, J., \& Lucas, K. (2008). Social exclusion: What can public transport offer? Transportation Economics, 22, 36-40.

Stanley, J., \& Stanley, J. (2004). Improving Public Transport to meet Community Needs: A Warrnambool Case-study. Melbourne: Bus Association Victoria and Warrnambool Bus Lines.

Stanley, J., \& Vella-Broderick, D. (2009). The usefulness of social exclusion to inform social policy in transport. Transport Policy Special Issue International Perspectives on Transport and Social Exclusion, 16, 90-96.

Tolley, R. S., \& Turton B. J. (1995). Transport Systems, Policy and Planning: A Geographical Approach. Harlow: Pearson Education Limited. 